
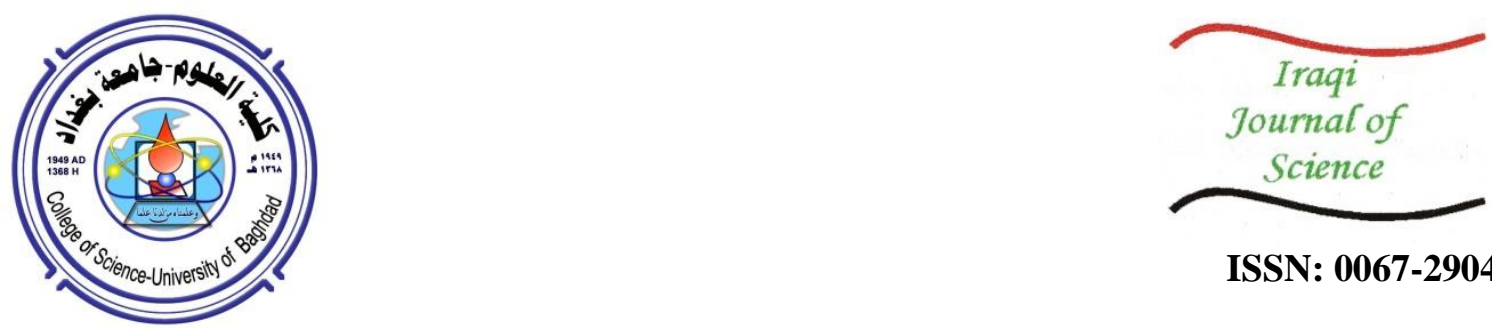

ISSN: 0067-2904

\title{
Improving the Iraqi Oil Well Cement Properties Using Barolift: an Experimental Investigation
}

\author{
Ali M. Hadi ${ }^{*}$, Ayad A. Al-Haleem \\ Department of Petroleum, College of Engineering, University of Baghdad, Baghdad, Iraq
}

Received: $15 / 2 / 2020$

Accepted: 3/5/2020

\begin{abstract}
Cement is a major component in oil and gas drilling operations that is used to maintain the integrity of boreholes by preventing the movement of formation fluids through the annular space and outside the casing. In 2019, Iraq National Oil Company ordered all international oil and gas companies which are working in Iraq to use Iraqi cement (made in Iraq) in all Iraqi oil fields; however, the X-ray fluorescence (XRF) and compressive strength results in this study show that this cement is not matching with American Petroleum Institute (API) standards.

During this study, barolift was used to improve the properties of Iraqi cement used in oil wells at high pressure and high temperature (HPHT). Barolift $(1 \mathrm{~g})$ was added to cement admixture to evaluate its influence on improving the performance of cement, mainly related to the property of toughness.

Primarily, the quality and quantity of cement contents were determined using X-ray fluorescence. Experiments were conducted to examine the characteristics of the base cement and the cement system containing $1 \mathrm{~g}$ of barolift, such as thickening time, free water, compressive strength, and porosity. X-ray diffraction (XRD), scanning electron microscope (SEM), and energy dispersive X-ray spectroscopy (EDS) were conducted for analyzing the microstructure of cement powder.

The experimental results showed that barolift acted as a retarder and improved the thickening time, slightly increased the free water, enhanced the mechanical properties, reduced the porosity, and aided in scheming new cement slurry to withstand the HPHT conditions. Microstructure analysis showed that barolift particles blocked the capillaries by filling cement spaces and, thus, a denser and stricter cement network was achieved.
\end{abstract}

Keywords: Oil well cement, fibres, barolift, compressive strength, microstructure analysis.

\section{تحسين جودة الاسمنت العراقي المستخدم في حفر الابار باستخدام الباروليفت

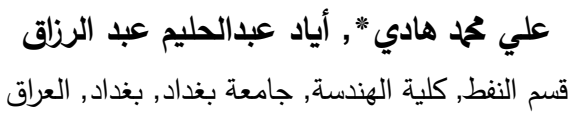

يعد الأسمنت مكونًا رئيسيًا في عملية حفر ابار النفط والغاز والذي يستخدم للحفاظ على سلامة تجويف

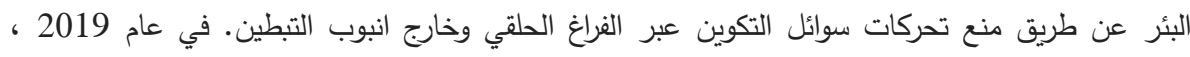

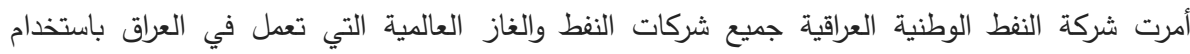

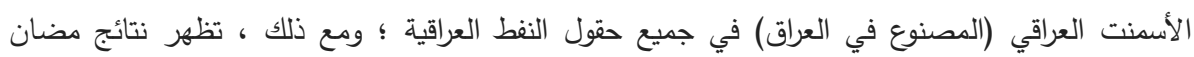

*Email: a.hadi1208@ coeng.uobaghdad.edu.iq 


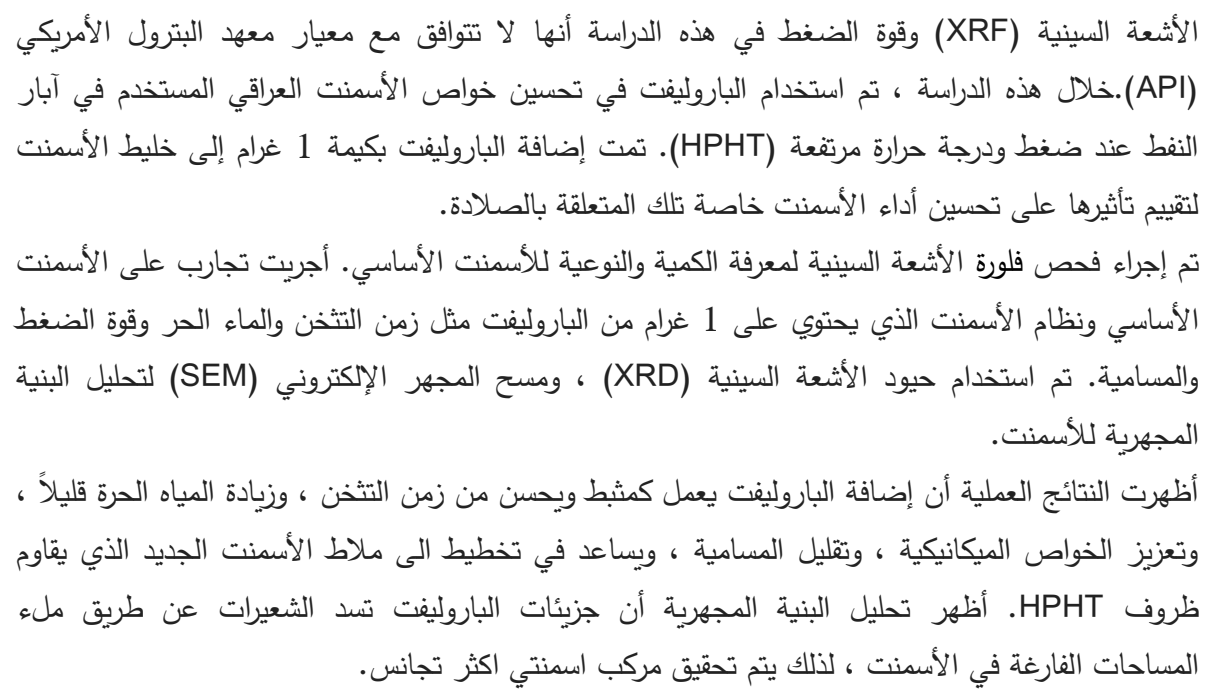

\section{Introduction}

Portland cement is one of the very essential components used excessively in the process of oil and/or gas well construction [1]. The cement slurry is positioned between the wall of the borehole and a metal casing in order to form a seal that supports the casing and avoid fluid migration [2]. The advantage of non-recurring engineering is attributable to the application of the well-cementing process; one of the most important factors in the whole oil well construction process is the safety of the cementing operation. The cement slurry must not prematurely set during it is being pumped, as it may block the well. Moreover, the cement should set in a short time to reduce costs due to delays [3].

There is only a limited number of studies on oil well cement, which utilized fiber to investigate and enhance the cement compressive strength, corrosion resistance, shrinkage, free water, thickening time, porosity, and permeability. However, none of these research investigated the effects of fiber on Iraqi oil well cement. One of those studies presented the effects of natural fiber (human hair) on oil well cement. Human hair $(0.4 \%$ volume ratio) with length of greater than $2 \mathrm{~cm}$ was introduced to oil well cement type I. Plastic shrinkage cracking test was conducted and the result showed that human hair decreased the shrinkage cracking area by $92 \%$ [4].

The other study showed the influence of the use of polypropylene fiber (PPF) on oil well cement. Polypropylene fiber $(0.25,0.5$ and $0.75 \%)$ by weight of cement (bwoc), in addition to silica floor and cement additives were introduced to cement class G. Thickening time, compressive strength, porosity, permeability, microstructure ( using SEM and XRD), density, and cement rheology tests were performed. It was found that PPF acts as an accelerator by reducing cement thickening time, enhancing cement compressive strength, decreasing cement porosity and permeability, and blocking the capillaries, as indicated by microstructural analysis. Furthermore, PPF does not alter the density and rheological properties of oil well cement [5].

Recently, a study investigated the effects of synthetic PPF on oil well cement. Polypropylene fiber $(0.125,0.25$ and $0.375 \%$ bwoc) was introduced to oil well cement class $\mathrm{G}$ to find out its capability to resist the carbonation, for the purpose of application of geologic carbon sequestration. Microstructure, permeability, compressive strength, and tensile strength tests were conducted after reacting with $\mathrm{CO} 2$ saturated $\mathrm{NaCl}$ brine $(0.5 \mathrm{M})$ for 10 and 20 days. The results showed that the addition of PPF decreased portlandite concentrations, as indicated by microstructural analysis, considerably decreased cement permeability, and enhanced the compressive strength of the set cement; therefore, this treatment improved the cement carbonation resistance [6].

This study investigates the capability of barolift as an added substance to Iraqi cement used in oil wells. Class $\mathrm{G}$ cement system was utilized to explore the impacts of barolift on different cement properties, such as thickening time, free water, compressive strength, and porosity within addition, microstructure analysis was conducted using XRD, SEM, and EDs of the cement specimens with and without the addition of barolift.

\section{Experimental Methodology}

In this research, all cement tests were performed in conformity with the API $10 \mathrm{~A}$ spec. $23^{\text {rd }}$ edition [7] to study the specific set cement properties. The techniques of XRF, XRD, SEM, and Energy 
dispersive X-ray spectroscopy (EDS) were also conducted for the microstructural analysis of the set cement.

\section{Materials}

The basic materials used are the Iraqi oil well cement class $G$ and barolift. Cement slurry was prepared using distilled water. Barolift used in this study (Figure -1) is a synthetic cellulose fiber of 0.5 inch length which is manufactured by Halliburton Oil and Gas Company. Barolift can be obtained during the manufacturing of rayon. It is the bi-product of the refining process that is mostly used in textile industry, being similar to artificial silk material.

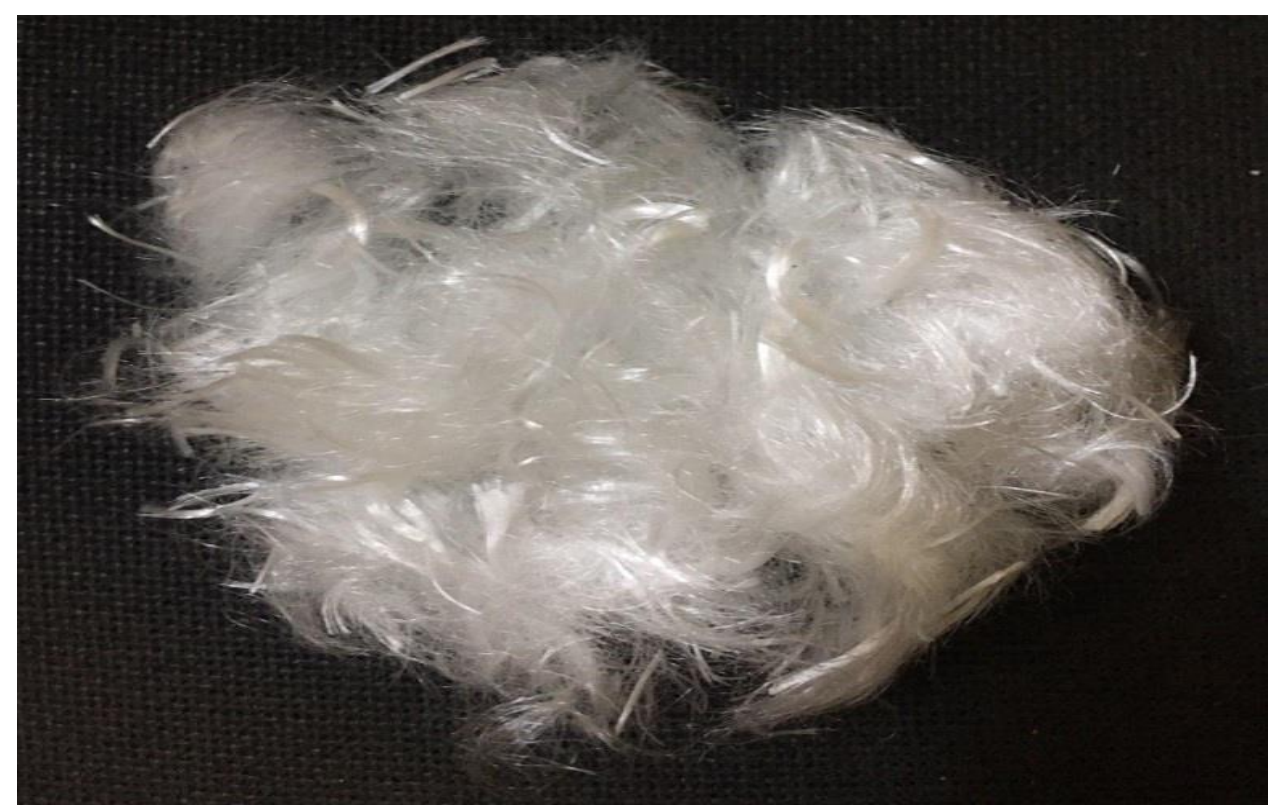

Figure 1- Barolift sample that have been used in this research

\section{Cement Slurry Design}

In the beginning, several cement tests were performed for the cement system design, as illustrated in the experimental part, without the addition of barolift. This series of tests was considered as a reference in the subsequent cement results. According to API 10A specification, oil well cement of $792 \mathrm{~g}$ weight was used with an amount of distilled water (44\% bwoc). Next, barolift of $1 \mathrm{~g}$ was added to the base cement mix to study its effects on cement properties. Slurry samples were prepared in conformity with API standard. OFITE's model 20 constant speed blender was used to prepare the slurry of cement for testing. The required mass of water was placed in the mixing container on the mixer base. The mixing speed was maintained at $4000 \mathrm{rpm}$ while the cement powder was added at a uniform rate during 15 seconds. The cover was placed on the mixing container and the mixing was continued at $12000 \mathrm{rpm}$ for 35 seconds. The same procedure was followed for the preparation of set cement slurry with the addition of $1 \mathrm{~g}$ of the barolift.

\section{The Measurements}

Before starting the measurement process, Iraqi oil well cement class $\mathrm{G}$ powder was subjected to $\mathrm{XRF}$ analysis to test its components. After cement slurry preparation, slurry properties such as thickening time and free water were measures. Cubical molds ( $2 * 2$ inch) were prepared according to API for compressive strength determination. Cement plugs of 1.5 inch in diameter were drilled from the cubes for porosity measurement. Microstructural tests (XRD, SEM and EDS) were conducted to analyze the structure of cement specimens.

\section{Results and Discussion}

\subsection{X-Ray Fluorescence of Base Cement}

X-ray florescence analysis was performed using Spectro XRF (model XEPOS 03 STD) to confirm the chemical composition of Iraqi oil well cement (HSR class G) and compare it with API standard composition of oil well cement, as shown in Table -1 . 
Table 1- XRF analysis results for Iraqi oil well cement as compared to API standard composition.

\begin{tabular}{|c|c|c|}
\hline Elements & Iraqi oil well cement & API standard \\
\hline $\mathrm{SiO}$ (Silicon oxide) & $19.29 \%$ & $24.66 \%$ \\
\hline $\mathrm{Al} 2 \mathrm{O} 3$ (Aluminum oxide) & $3.123 \%$ & $5.6 \%$ \\
\hline $\mathrm{Fe} 2 \mathrm{O} 3$ (Iron oxide) & $0.5413 \%$ & $0.38 \%$ \\
\hline $\mathrm{CaO}$ (Calcium oxide) & $72.82 \%$ & $61.87 \%$ \\
\hline $\mathrm{MgO}$ (Magnesium oxide) & $1.772 \%$ & $0.9 \%$ \\
\hline $\mathrm{SO} 3$ (sulfur oxide) & $3.131 \%$ & $1.51 \%$ \\
\hline
\end{tabular}

The results reveal obvious differences in elements concentrations between Iraqi oil well cement and API standard, which may cause a reduced quality of Iraqi cement and, subsequently, reduced mechanical properties. One of the most important notes is that the proportion of calcium oxide was greater than that in the standard composition, which may cause a decrease in the strength of oil well cement and the beginning of the expansion process.

\subsection{Thickening Time}

The thickening time of cement slurry indicates how long the cement will remain pumpable under specific downhole conditions. This time parameter for a given cement slurry must be known before using the slurry in a cementing operation. Thickening time test was conducted using OFITE's model 120 HPHT Consistometer. Table -2 demonstrates the thickening time results for the base cement and for cement system containing $1 \mathrm{~g}$ of barolift.

Table 2- Summarized thickening time results for base cement and cement system containing $1 \mathrm{~g}$ of barolift compared with API 10A requirements.

\begin{tabular}{|c|c|c|}
\hline \multirow{2}{*}{ Samples description } & \multicolumn{2}{|c|}{ Thickening time at 52 ${ }^{\circ} \mathbf{C}$ and 5160psi. } \\
\cline { 2 - 3 } & Consistency at 30 min & $\begin{array}{c}\text { Thickening time in minutes } \\
\text { (100Bc) }\end{array}$ \\
\hline Base cement & 16 & 91 \\
\hline $\begin{array}{c}\text { Cement system containing 1g } \\
\text { of barolift }\end{array}$ & 14 & 100 \\
\hline API requirements & $<30$ & $90-120$ \\
\hline
\end{tabular}

As it is clear from Table -2 , the thickening time (100 Bearden unit of consistency $(\mathrm{Bc})$ ) of net cement without additives is within acceptable range of API (90-120 min), while the addition of barolift $(1 \mathrm{~g})$ increased the cement thickening time $(\mathrm{Bc}=100)$ by $9.8 \%$. Furthermore, according to API 10A, the maximum accepted consistency during a stirring period of 15-30 min should be $30 \mathrm{Bc}$ for all classes of cement. Therefore, the net cement and the sample containing barolift of $1 \mathrm{~g}$ had consistency values of less than $30 \mathrm{Bc}$ at $30 \mathrm{~min}$, which conforms to the requirements of API 10A specifications. The reason of the improvement in the thickening time is attributed to the fact that the addition of barolift reduces the reaction of oil well cement at early time of hydration process and, therefore, cement thickening time is increased.

\subsection{Free Water}

Free water is defined as the separation of water from cement slurry, once it has been placed, which can lead to channel formation and gas migration problems, particularly in deviated wells. Table -3 illustrates the volume of free water in the samples of base cement and cement system containing $1 \mathrm{~g}$ of barolift, as determined by using OFITE model 60 Atmospheric Consistometer. 
Table 3- Summarized free water results for base cement and cement system containing $1 \mathrm{~g}$ of barolift compared with API 10A standards.

\begin{tabular}{|c|c|c|}
\hline Samples description & Volume of free water $(\mathbf{m l})$ & Volume fraction $(\boldsymbol{\%})$ \\
\hline Base cement & 7.5 & 1.8 \\
\hline $\begin{array}{c}\text { Cement system containing 1g } \\
\text { of barolift }\end{array}$ & 8.5 & 2.125 \\
\hline API requirements & N/A & $<5.9$ \\
\hline
\end{tabular}

From the results in Table -3 , it is clear that the amount of free water of the base cement sample was within the acceptable range of API requirements. Furthermore, the addition of barolift of $1 \mathrm{~g}$ caused a slight increase in cement free water $(18 \%)$. This effect may be attributed to the notion that barolift acts in filling the voids, which leads to more water separation.

\subsection{Compressive Strength}

The compressive strength is the force of compression per unit of cross-sectional area required to crush a set cement sample. Properly designed cement slurry will set after it has been placed in its appropriate location within the well. Table -4 lists the compressive strength results for the base cement and cement matrix containing $1 \mathrm{~g}$ of barolift for two temperature values $\left(38^{\circ} \mathrm{C}\right.$ and $\left.60^{\circ} \mathrm{C}\right)$, as tested by using OFITE model 250.

Table 4- Summarized compressive strength results for base cement and cement system containing $1 \mathrm{~g}$ of barolift compared with API 10A standards.

\begin{tabular}{|c|c|c|}
\hline \multirow{2}{*}{ Samples description } & \multicolumn{2}{|c|}{ Compressive strength (Psi) } \\
\cline { 2 - 3 } & Eight hours at 38 ${ }^{\circ} \mathbf{C}$ & ${\text { Eight hours at } \mathbf{6 0}^{\circ} \mathbf{C}}^{\circ}$ \\
\hline Base cement & 527 & 1399 \\
\hline $\begin{array}{c}\text { Cement system containing 1g } \\
\text { of barolift }\end{array}$ & 518 & 1808 \\
\hline API requirements & $>300$ & $>1500$ \\
\hline
\end{tabular}

The results in Table- 4 show that the compressive strength of base cement at a temperature of $38^{\circ} \mathrm{C}$ is acceptable according to the API standard specification 10A (exceed $300 \mathrm{psi}$ ), while the results at a temperature of $60{ }^{\circ} \mathrm{C}$ are not satisfactory compared to the API specification $10 \mathrm{~A}$ (do not exceed 1500 psi). This can be attributed to the fact that the high temperature curing can have a negative impact on early strength development. In such cases, micro-structural changes are reported, while pore size and distribution were different. It is reported that these differences may be caused by deficiency/escape of water from the mixture.

The compressive strength of the cement system containing $1 \mathrm{~g}$ of barolift at $38^{\circ} \mathrm{C}$ is very asymptotic to that of the base cement. The reason of the slight decrease in compressive strength is the fact that the addition of barolift reduces the reaction of oil well cement at ordinary temperature of hydration process. The compressive strength of this system at $60^{\circ} \mathrm{C}$ shows an increase of $29 \%$. This improvement in compressive strength is due to the ability of barolift to control micro cracking growth by making strong cross links between cement particles at high temperature. The main mechanism of the fiber is creating a mesh network which might enhance the strength of the cement as well as providing additional control of circulation losses [5]. In addition, barolift can accelerate the pozzolanic reaction and form more $\mathrm{C}-\mathrm{S}-\mathrm{H}$ products, as indicated by the microstructural analysis.

\subsection{Porosity}

Porosity is a very essential property for the set cement sheath which needs to be improved for the long term performance of the set cement. Table -5 shows porosity results of the base cement and cement system containing $1 \mathrm{~g}$ of barolift, after curing for eight hours at $60^{\circ} \mathrm{C}$, as tested by using PHI220 Helium Porosimeter. 
Table 5- Comparison of the results of porosity measurements for the base cement and cement system containing $1 \mathrm{~g}$ barolift.

\begin{tabular}{|c|c|c|c|c|c|c|c|}
\hline Sample & $\begin{array}{c}\text { Length } \\
(\mathrm{cm})\end{array}$ & $\begin{array}{c}\text { Diameter } \\
(\mathrm{cm})\end{array}$ & $\begin{array}{c}\text { Bulk } \\
\text { volume } \\
\left(\mathrm{cm}^{3}\right)\end{array}$ & $\begin{array}{c}\text { Weight } \\
(\mathrm{g})\end{array}$ & $\begin{array}{c}\text { Pore } \\
\text { volume } \\
\left(\mathrm{cm}^{3}\right)\end{array}$ & $\begin{array}{c}\text { Grain } \\
\text { volume } \\
\left(\mathrm{cm}^{3}\right)\end{array}$ & $\begin{array}{c}\text { Porosity } \\
(\%)\end{array}$ \\
\hline Net cement & 4.35 & 3.8 & 49.334 & 91.16 & 2.141 & 47.193 & 4.339 \\
\hline $\begin{array}{c}\text { Cement with } \\
\text { 1g barolift }\end{array}$ & 4.1 & 3.8 & 46.499 & 86.45 & 1.988 & 44.51 & 4.276 \\
\hline
\end{tabular}

From Table -5 , it is evident that the addition of barolift $(1 \mathrm{~g})$ causes a slight change in porosity, as indicated by a decrease by $1.5 \%$. These effects on the porosity of cement class $\mathrm{G}$ is due to the fact that the barolift particles fill the capillary porous and hence, reduce the voids present in the solidified cement matrix.

\subsection{Microstructure Analysis}

Cement hydration process starts when water is added to Portland cement [6]. During this process the cement components will be converted mainly to calcium silicate hydrates (C-S-H), calcium hydroxide $(\mathrm{CH})[8,9,10]$, and a very small amount of ettringite (AFt) [11]. Also, un-hydrated products of $\mathrm{C}_{2} \mathrm{~S}$ and $\mathrm{C}_{3} \mathrm{~S}$ may exist with a very low concentration [12]. The hydration products with low $\mathrm{Ca} / \mathrm{Si}$ ratio are desired since they improve the strength of the cement sheath and are resistance to reactions with acids and fluids. Thus, it is preferred for the hydrated cement to have higher content of calcium silicate hydrates and lower concentration of calcium hydroxides [6, 13, 14].

\subsubsection{X-ray diffraction}

$\mathrm{X}$-ray diffraction is a well-known methodology that is used to detect crystalline compounds. A cement specimen class $\mathrm{G}$ having barolift of $1 \mathrm{~g}$ was subjected to a Philips model X'Pert Pro device after curing for eight hours at $60 \mathrm{C}^{\circ}$. Figures-(2 and 3) summarize the results.

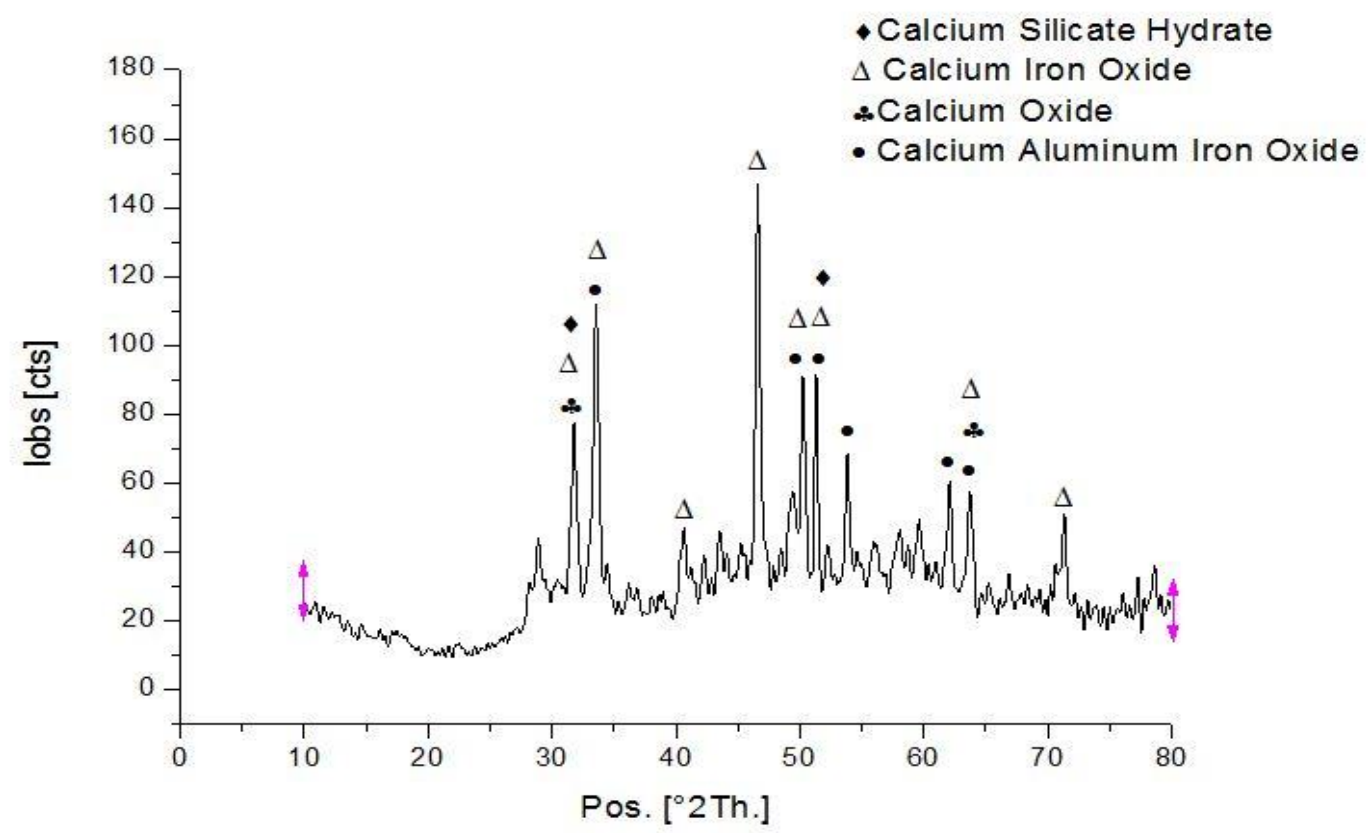

Figure 2- XRD patterns for the base cement after curing for 8 hours at $60^{\circ} \mathrm{C}$ 


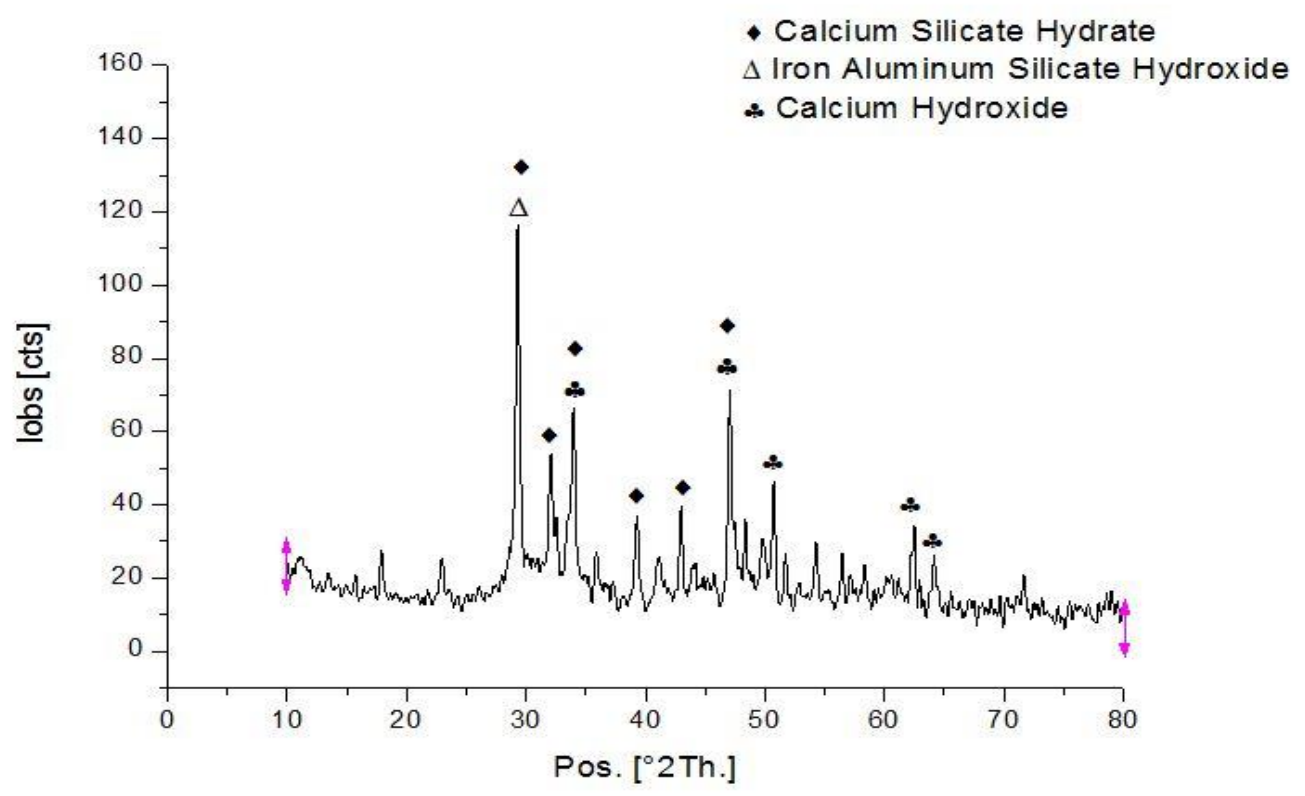

Figure 3- XRD patterns for the cement specimen having barolift of $1 \mathrm{~g}$ after curing for 8 hours at $60^{\circ} \mathrm{C}$ Figures and 3 compare the hydration products for the base cement with the cement samples incorporating $1 \mathrm{~g}$ of barolift. As indicated in Figure -2, the base cement contains many hydration products and it is dominated by calcium iron oxide and calcium aluminum iron oxide. Sample with $1 \mathrm{~g}$ of barolift, as indicated in Figure -3 , is dominated by calcium silicate hydrates as indicated by the 2 theta of about $29^{\circ}$. This result confirms the ability of using barolift particles to improve the quality and integrity of the cement.

\subsubsection{Scanning Electron Microscope}

Scanning electron microscope was used to define the hydration products of different cement slurries. It was conducted to comprehend the compressive strength and porosity results. Curing temperature is a very important property that the hydration products of the cement depend on. During this research, cement specimens were cured for eight hours at $60 \mathrm{C}^{\circ}$ and then cracked to expose the unexposed surface. After that, the specimens were subjected to SEM examination (TESCAN model MIRA3). Figures-(4 and 5) summarize the results.
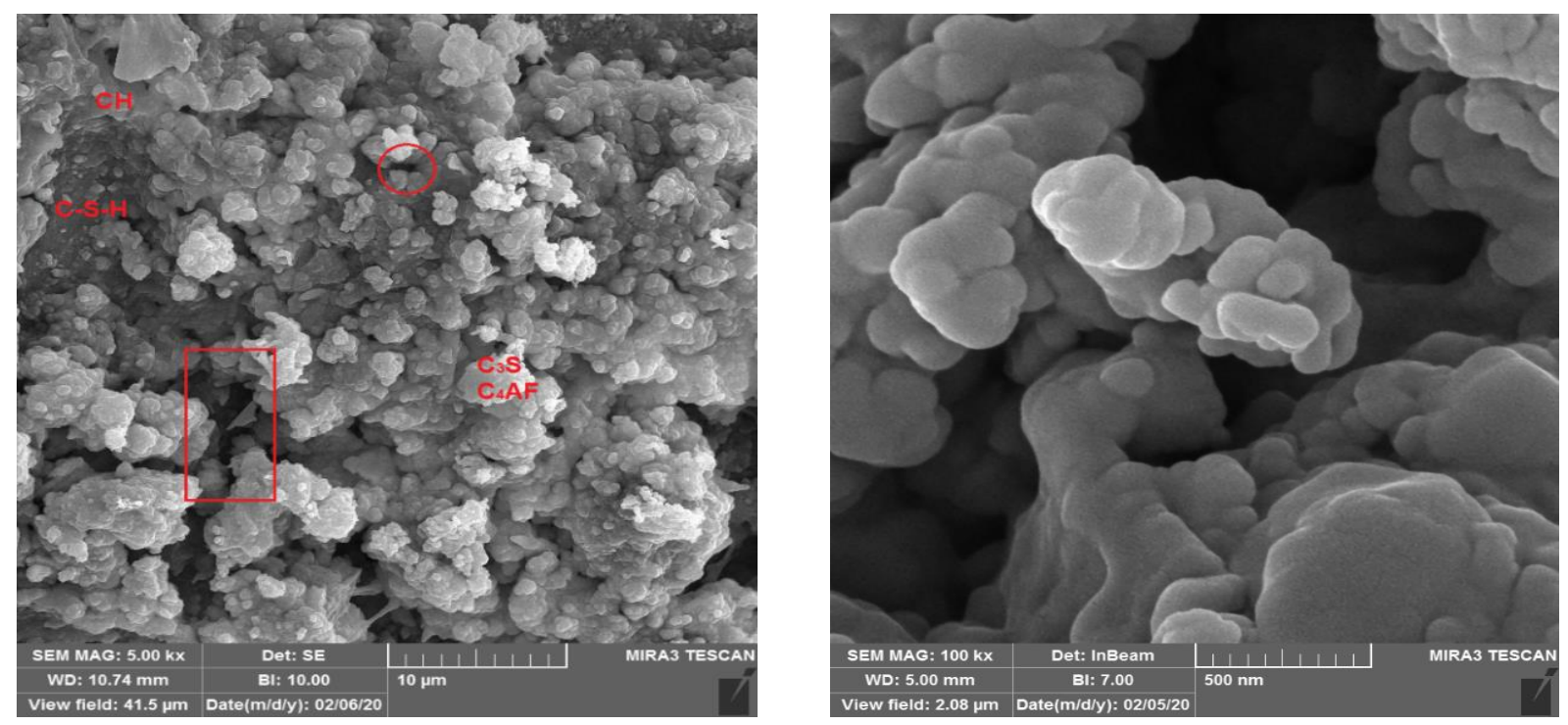

Figure 4- SEM image of set class G cement specimen cured at 60C for 8 hours. 
It is worth to note from Figure -4 that a significant void space is clearly visible (indicated by circles), while large and many groves are also observed (rectangle). Large quantities of anhydrate cement (C3S and $\mathrm{C} 4 \mathrm{AF}$ ) were found, with the existence of several $\mathrm{CH}$ crystals which are linked to the $\mathrm{C}-\mathrm{S}-\mathrm{H}$ gel and cover a large area, indicating that the hydration process was not completed. In addition, C-S-H gel concentration was too low. All the above observations explain the resultant low compressive strength and high porosity.
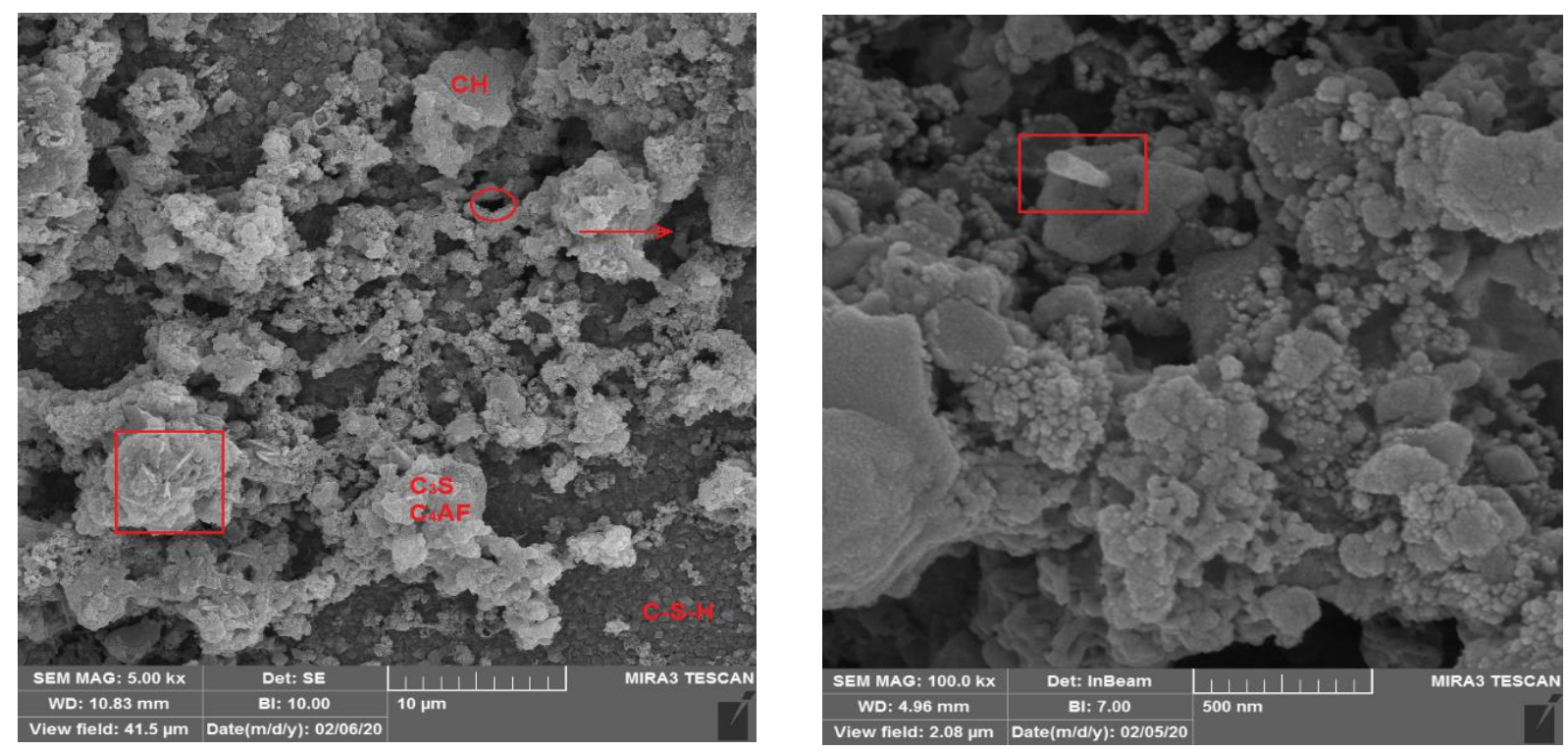

Figure 5- SEM image of cement specimens containing $1 \mathrm{~g}$ of barolift and cured at $60 \mathrm{C}$ for 8 hours.

Figure -5 shows a slight decrease in pore space (indicated by circles) and few small groves (arrows). The concentration of $\mathrm{C}-\mathrm{S}-\mathrm{H}$ gel is high and covers a large area of the specimen. Less quantities of anhydrate cement are clearly visible compared with the base cement (C3S and C4AF). The existence of small $\mathrm{CH}$ crystals linked to the $\mathrm{C}-\mathrm{S}-\mathrm{H}$ gel which covers a small area indicates that the process of hydration was almost completed. All the above observations explain the results of high compressive strength and the slightly decreased porosity. Moreover, the addition of barolift appears to lead to the formation of a dense and an ideal network structure in the final resulted cement specimen.

\subsubsection{Energy dispersive $X$-ray spectroscopy}

Energy dispersive X-ray spectroscopy test was conducted using a TESCAN model MIRA3 device in order to demonstrate the weight analysis for the base cement and cement systems containing of $1 \mathrm{~g}$ barolift cured at $60 \mathrm{C}^{\circ}$ for eight hours. Figures-(6 and 7) illustrate the results.

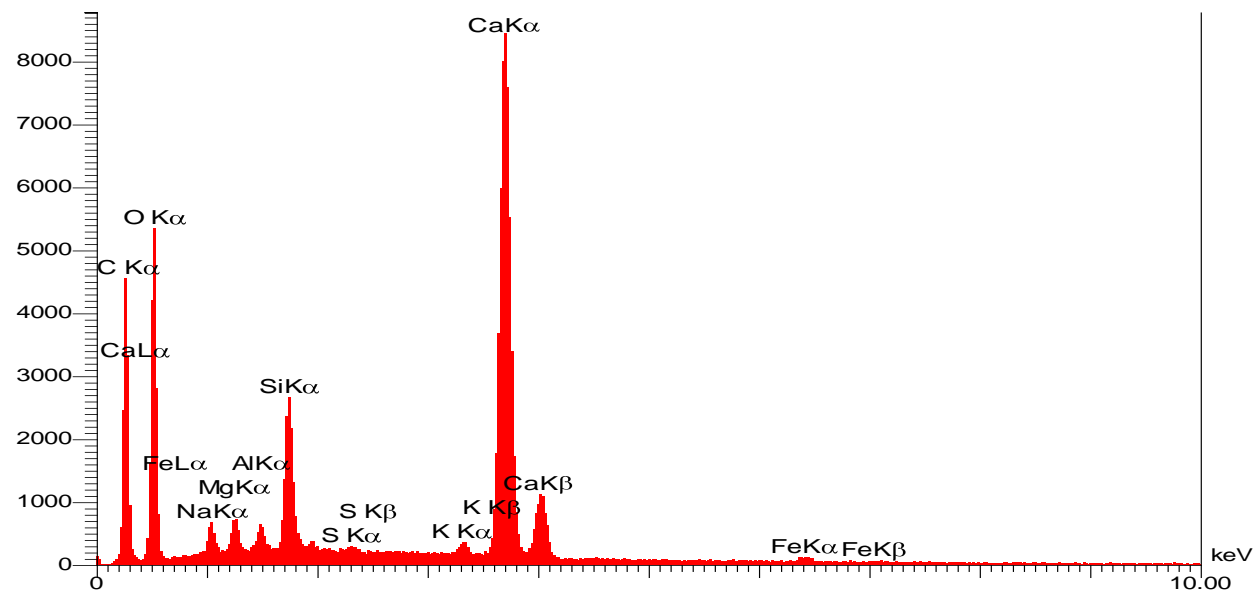

Figure 6- EDS pattern of set class G cement specimen cured at $60 \mathrm{C}$ for 8 hours. 
As it is clear from Figure -6 , the final cement product has a large weight percentage of calcium, which established the formation of C-S-H gel in the final hardened cement.

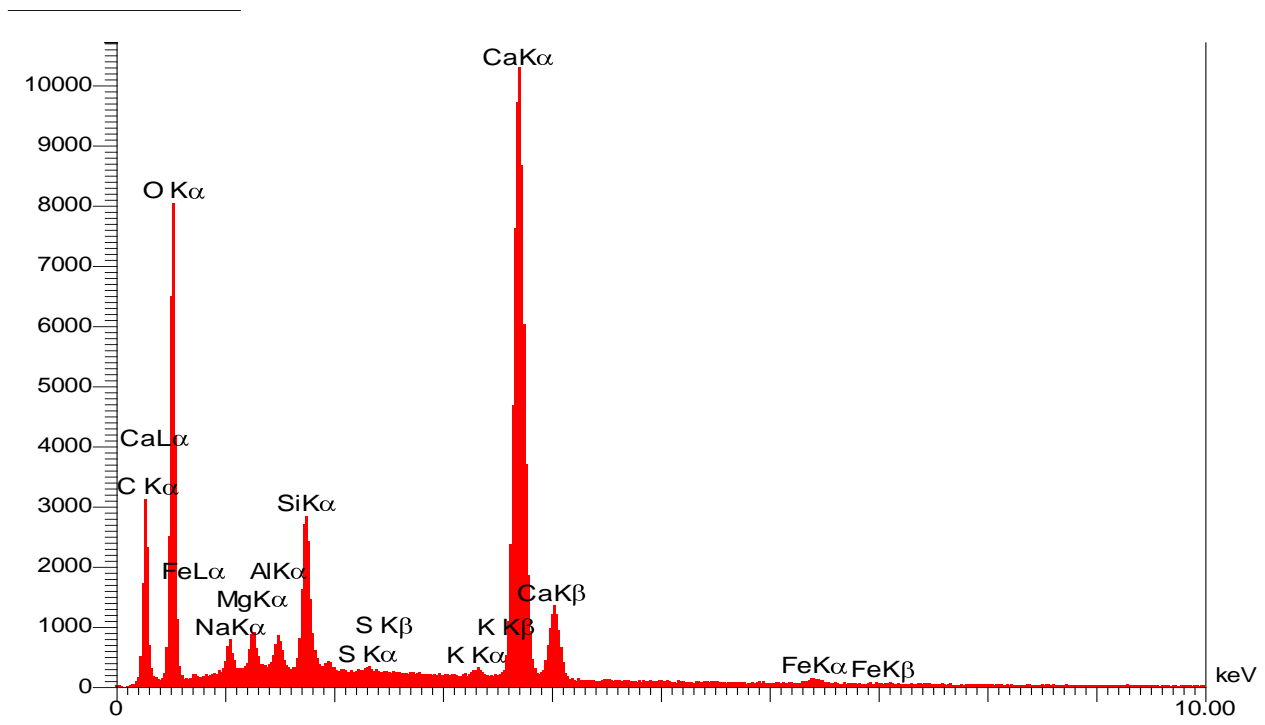

Figure 7- EDS pattern of cement specimens containing $1 \mathrm{~g}$ of barolift cured at $60 \mathrm{C}$ for 8 hours.

Figure -7 demonstrates that the final cement product has a higher weight percentage of calcium, which established the formation of a higher percentage of C-S-H gel in the final hardened cement.

\section{Conclusions}

In this research, barolift was added to show the significant impact on raw cement manufactured in Iraq. Barolift enhanced the cement thickening time $(\mathrm{Bc}=100)$ to reach 100 min and remarkably improved the compressive strength of cement at a temperature of $60 \mathrm{C}^{\circ}$ to reach $1808 \mathrm{Psi}$. These results indicate an additional value to enhance recent manufactured cement, with a higher matching to the API standards.

Finally, it is recommended to use of barolift as an additive to enhance Iraqi oil well cement by the Iraqi Ministry of Oil and the Ministry of Industry and Minerals.

\section{Acknowledgement}

We would like to show our gratitude to Dunia K. Mahdi, Ahmed T. Almomen and Ahmed Abdulhamid Mahmoud for sharing insight and comments.

\section{References}

1. Garnier, A., Fraboulet, B., Saint-Marc, J. and Bois, A. 2007. January. Characterization of cement systems to ensure cement sheath integrity. In Offshore Technology Conference. Offshore Technology Conference.

2. Nelson EB. And Guillot D. 2006. Well cementing. 2nd ed. Sugar Land, TX: Schlumberger Dowell.

3. Jupe, A.C., Wilkinson, A.P., Luke, K. and Funkhouser, G.P. 2005. Class H oil well cement hydration at elevated temperatures in the presence of retarding agents: An in situ high-energy Xray diffraction study. Industrial \& engineering chemistry research, 44(15): 5579-5584.

4. Al-Darbi, M.M., Saeed, N.O., Ajijolaiya, L.O. and Islam, M.R. 2006. A novel oil well cementing technology using natural fibers. Petroleum science and technology, 24(11): 1267-1282.

5. Ahmed, A., Gajbhiye, R., Elkatatny, S., Kalimur Rahman, M., Sarmah, P. and Yadav, P. 2018. June. Enhancing the Cement Quality Using Polypropylene Fibers. In SPE Trinidad and Tobago Section Energy Resources Conference. Society of Petroleum Engineers.

6. Mahmoud, A.A. and Elkatatny, S. 2020. Improving Class G Cement Carbonation Resistance for Applications of Geologic Carbon Sequestration Using Synthetic Polypropylene Fiber. Journal of 
Natural Gas Science and Engineering. 76.

7. API Specification 10A/ISO 10426-1, 2002. Specification for Cements and Materials for Well Cementing, Twenty-third Edition.

8. Brouwers, H. 2004. The work of Powers and Brownyard revisited: part 1. Cement and Concrete Research, 34(9):1697-1716.

9. MacLaren, D.C. and White, M.A. 2003. Cement: its chemistry and properties. Journal of Chemical Education, 80: 623-635. https://doi.org/10.1021/ed080p623.

10. Duguid, A., Radonjic, M. and Scherer, G.W. 2011. Degradation of cement at the reservoir/cement interface from exposure to carbonated brine. International Journal of Greenhouse Gas Control, 5: 1413-1428. https://doi.org/10.1016/j.ijggc.2011.06.007.

11. Abid, K., Gholami, R., Choate, P. and Nagaratnam, B.H. 2015. A review on cement degradation under CO2-rich environment of sequestration projects. Journal of Natural Gas Science and Engineering, 27: 1149-1157.

12. Bahafid, S., Ghabezloo, S., Duc, M., Faure, P. and Sulem, J. 2017. Effect of the hydration temperature on the microstructure of class G cement: C-S-H composition and density, Cement and Concrete Research, 95: 270-281.

13. Mahmoud, A.A., Elkatatny, S., Ahmed S., A. and Gajbhiye, R. 2019. Influence of Nanoclay Content on Cement Matrix for Oil Wells Subjected to Cyclic Steam Injection. Materials, 12(9): 1452. https://doi.org/10.3390/ma12091452.

14. Yang, Y., Yuan, B., Wang, Y., Zhang, S. and Zhu, L. 2016. Carbonation resistance cement for CO2 storage and injection wells. Journal of Petroleum Science and Engineering, 146: 883-889. https://doi.org/10.1016/j.petrol.2016.08.006. 